\title{
The diabetes epidemic and its effect on cardiac surgery practice
}

\author{
Sajjad Raza, MD, ${ }^{a}$ Eugene H. Blackstone, MD, ${ }^{a, b}$ and Joseph F. Sabik III, MD ${ }^{a}$
}

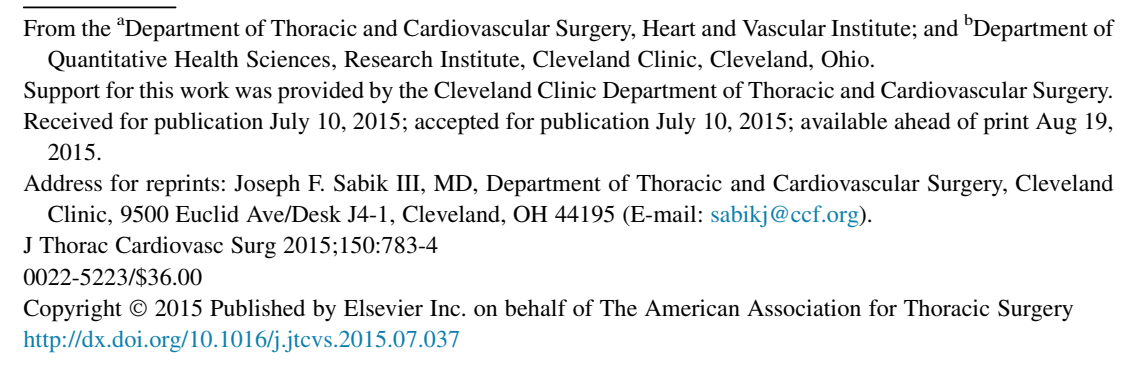

\section{THE EPIDEMIC}

The diabetes epidemic is one of the most challenging public health issues of the 21 st century, responsible for 4.9 million deaths worldwide in 2014 - one every 7 seconds. ${ }^{1}$ According to the World Health Organization, excess body weight and physical inactivity are the 2 main culprits leading to diabetes, which is now developing at younger ages. ${ }^{2}$ The difficulty of altering diet and lifestyle habits portends a future of ever-increasing prevalence. With diabetes comes development of coronary artery disease, which is not only common in diabetic patients, but also their major cause of death. ${ }^{3,4}$ Therefore, it is not surprising that the proportion of patients presenting for coronary artery bypass grafting (CABG) who have diabetes is also on the rise, as confirmed by our study ${ }^{5}$ published in the August 2015 issue of the Journal, nor is the fact that they need to be treated optimally to maximize survival.

\section{EFFECT ON PRACTICE}

We investigated outcomes of 10,362 medically treated diabetic patients and 45,139 nondiabetic patients who underwent primary isolated CABG from 1972 to 2011. The proportion of patients undergoing coronary surgery who had diabetes skyrocketed, from $7 \%$ in the 1970 s to $40 \%$ in 2010. This experience is not isolated. Zhang and colleagues $^{6}$ examined outcomes of 9240 patients undergoing primary isolated $\mathrm{CABG}$ at Fuwai Hospital in Beijing between 1999 and 2008; of these, 2682 had diabetes. Diabetic patients comprised $20 \%$ of the CABG population in 1999 , but $32 \%$ in 2008 . An analysis ${ }^{7}$ of the Society of Thoracic Surgeons database also showed an increase in the proportion of patients undergoing CABG who had diabetes, from $33 \%$ in 2000 to $40 \%$ in 2009 .

\section{EFFECT ON EARLY OUTCOMES AND COST OF TREATMENT}

In our experience, occurrence of in-hospital complications and long-term survival (up to 20 years) was worse in diabetic patients, and the direct technical cost (the sum of direct preoperative, operative, and postoperative

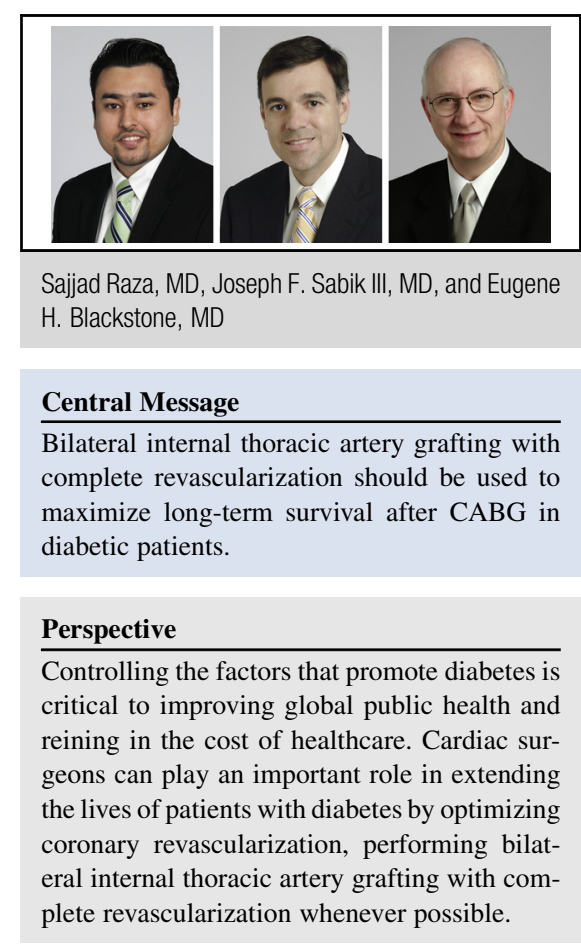

expenditures) of $\mathrm{CABG}$ was $9 \%$ higher than that for nondiabetic patients, a difference driven mainly by clinical and laboratory tests, imaging studies, medicines, nursing costs, and longer intensive care unit and postoperative stays. Again, ours are not isolated findings. China has the largest number of people with diabetes in the world-more than 100 million. $^{6}$ The report of Zhang and colleagues ${ }^{6}$ discusses this population. Adjusted hospital death after primary isolated $\mathrm{CABG}$ was similar for diabetic and nondiabetic patients. In-hospital costs, medication costs, and total costs of $\mathrm{CABG}$ at 2 years were higher in diabetic patients ( $\$ 66,000$ vs $\$ 77,000 ; P<.001)$.

\section{EFFECT ON MANAGING CORONARY ARTERY DISEASE}

Diabetic patients represent an important population presenting for treatment of coronary artery disease. The BARI (Bypass Angioplasty Revascularization Investigation) 2D trial ${ }^{8}$ demonstrated that CABG is better than medical therapy, and the FREEDOM (Future Revascularization Evaluation in Patients With Diabetes Mellitus: Optimal Management of Multivessel Disease) trial $^{9}$ demonstrated that $\mathrm{CABG}$, rather than percutaneous coronary intervention, is the revascularization strategy of choice for diabetic patients with multivessel disease. However, although fewer adverse events occurred after $\mathrm{CABG}$ than after percutaneous 


\section{Abbreviations and Acronyms \\ BARI = Bypass Angioplasty \\ Revascularization Investigation \\ CABG = coronary artery bypass grafting \\ FREEDOM $=$ Future Revascularization Evaluation \\ in Patients With Diabetes Mellitus: \\ Optimal Management of Multivessel \\ Disease}

coronary intervention in diabetic patients, their long-term survival after coronary surgery was worse than that of nondiabetic patients. In addition, we observed worse long-term survival among diabetic patients after CABG, and Zhang and colleagues ${ }^{6}$ documented that long-term outcomes (up to 10 years), including mortality, stroke, and major adverse cardiovascular and cerebrovascular events, were worse in diabetic patients, as was occurrence of rehospitalization for heart failure and stroke.

These adverse long-term results after CABG could be due to at least 2 factors. First, coronary surgery may be less effective in diabetic than in nondiabetic patients, owing to worse graft patency. However, angiographic data from the BARI trial showed similar patency of internal thoracic artery and saphenous vein grafts in diabetic and nondiabetic patients. ${ }^{10}$ Second, diabetic patients have more comorbid conditions, either caused by or associated with diabetes, than do nondiabetic patients. ${ }^{5}$

Thus, the prevalence of cardiovascular risk factors, such as obesity and hypertension in our study, has increased across time in general, but more so in diabetic than nondiabetic patients. When the cause of death was compared 5 years after coronary revascularization in the BARI trial, ${ }^{11}$ cardiac mortality was similar- $5.8 \%$ in diabetic versus $4.7 \%$ in nondiabetic patients-just as it was in the study of Zhang and colleagues in China, but noncardiac mortality was strikingly higher $(12.2 \%$ vs $4.8 \%$, respectively). Thus, worse long-term survival after CABG in diabetic patients is more likely due to their greater comorbidity burden than to ineffectiveness of CABG.

\section{EFFECT ON SOCIETY}

Coupled with the greater expense of bypass surgery in diabetic patients, this upward trend in prevalence of diabetes contributes importantly to the growing healthcare cost crisis. Currently, 25.8 million people in the United States have diabetes, and by 2034, that number is projected to reach 44.1 million. ${ }^{12,13}$ Even more alarming, the Centers for Disease Control and Prevention projects ${ }^{14}$ that if current trends continue, 1 in 3 US adults could have diabetes by 2050 ! This increase will lead to a further rise in the prevalence of coronary artery disease in the population, and to the need for revascularization.
Clearly, policies and programs focused on controlling the factors that promote diabetes are critical to improving global public health and reining in the rising cost of healthcare. In the meantime, cardiac surgeons can play an important role in extending the lives of patients with diabetes by optimizing coronary revascularization, performing bilateral internal thoracic artery grafting with complete revascularization whenever feasible. ${ }^{15}$

\section{Conflict of Interest Statement}

Dr Sabik is the North American principal investigator for the Abbott Laboratories-sponsored left main coronary disease randomized trial (EXCEL), is on the Society for Thoracic Surgeons Board of Directors, and is on the scientific advisory board of Medtronic. All other authors have nothing to disclose with regard to commercial support.

\section{References}

1. International Diabetes Federation (IDF). IDF Diabetes Atlas. 6th ed. Brussels: IDF; 2013. Available at: http://www.idf.org/diabetesatlas. Accessed July 6, 2015.

2. World Health Organization. WHO diabetes fact sheet. Available at: http://www. who.int/mediacentre/factsheets/fs312/en/. Accessed July 7, 2015.

3. Grundy SM, Benjamin IJ, Burke GL, Chait A, Eckel RH, Howard BV, et al. Diabetes and cardiovascular disease: a statement for healthcare professionals from the American Heart Association. Circulation. 1999;100:1134-46.

4. Bax JJ, Young LH, Frye RL, Bonow RO, Steinberg HO, Barrett EJ. Screening for coronary artery disease in patients with diabetes. Diabetes Care. 2007;30:2729-36.

5. Raza S, Sabik JF III, Ainkaran P, Blackstone EH. Coronary artery bypass grafting in diabetics: a growing health care cost crisis. J Thorac Cardiovasc Surg. 2015; 150:304-12.

6. Zhang H, Yuan X, Osnabrugge RL, Meng D, Gao H, Zhang S, et al. Influence of diabetes mellitus on long-term clinical and economic outcomes after coronary artery bypass grafting. Ann Thorac Surg. 2014;97:2073-9.

7. El Bardissi AW, Aranki SF, Sheng S, O’Brien SM, Greenberg CC, Gammie JS Trends in isolated coronary artery bypass grafting: an analysis of the Society of Thoracic Surgeons adult cardiac surgery database. J Thorac Cardiovasc Surg. 2012;143:273-81

8. A randomized trial of therapies for type 2 diabetes and coronary artery disease. N Engl J Med. 2009;360:2503-15.

9. Farkouh ME, Domanski M, Sleeper LA, Siami FS, Dangas G, Mack M, et al. Strategies for multivessel revascularization in patients with diabetes. $N$ Engl J Med. 2012;367:2375-84.

10. Schwartz L, Kip KE, Frye RL, Alderman EL, Schaff HV, Detre KM. Coronary bypass graft patency in patients with diabetes in the Bypass Angioplasty Revascularization Investigation (BARI). Circulation. 2002;106:2652-8.

11. Influence of diabetes on 5-year mortality and morbidity in a randomized trial comparing CABG and PTCA in patients with multivessel disease: the Bypass Angioplasty Revascularization Investigation (BARI). Circulation. 1997;96: 1761-9.

12. Centers for Disease Control and Prevention (CDC). National diabetes fact sheet: national estimates and general information on diabetes and prediabetes in the United States, 2011. Atlanta: US Department of Health and Human Services, CDC; 2011.

13. Huang ES, Basu A, O'Grady M, Capretta JC. Projecting the future diabetes population size and related costs for the U.S. Diabetes Care. 2009;32:2225-9.

14. Centers for Disease Control and Prevention. Number of Americans with diabetes projected to double or triple by 2050 . Available at: http://www.cdc.gov/media/ pressrel/2010/r101022.html. Accessed July 6, 2015.

15. Raza S, Sabik JF III, Masabni K, Ainkaran P, Lytle BW, Blackstone EH. Surgical revascularization techniques that minimize surgical risk and maximize late survival after coronary artery bypass grafting in patients with diabetes mellitus. J Thorac Cardiovasc Surg. 2014;148:1257-64; discussion 64-6.

Key Words: coronary artery bypass grafting, diabetes, cost 